\title{
A Research Agenda on Open Innovation and Entrepreneurship: A Co-Word Analysis
}

\author{
Marta Ortiz-de-Urbina-Criado *, ${ }^{+}$(D) , Juan-José Nájera-Sánchez ${ }^{\dagger}$ and \\ Eva-María Mora-Valentín + (iD \\ Facultad de Ciencias Jurídicas y Sociales, Universidad Rey Juan Carlos, Paseo de los Artilleros, s/n, \\ 28032 Madrid, Spain; juanjose.najera@urjc.es (J.-J.N.-S.); evamaria.mora@urjc.es (E.-M.M.-V.) \\ * Correspondence: marta.ortizdeurbina@urjc.es; Tel.: +34-91-488-7677 \\ t These authors contributed equally to this work.
}

Received: 28 May 2018; Accepted: 6 July 2018; Published: 10 July 2018

check for updates

\begin{abstract}
This paper aims to contribute to a better understanding of the literature on open innovation and entrepreneurship. Several studies have applied bibliometric methods to innovation and entrepreneurship separately. However, no study has considered these fields in combination while using a bibliometric approach. The main aim of this paper is to understand the relationship between open innovation and entrepreneurship. We develop a descriptive analysis, focusing on temporal evolution, journals, authors, universities, countries, and keywords, and a co-word analysis. Our research identifies the main topics investigated in the open innovation and entrepreneurship literature and describes their relationships. Based on our results, the topics are grouped in three clusters. We present observations on how this literature is influenced by the resources and how this literature affects the management of innovation and knowledge. Future research could focus on questions such as the advantages of open innovation in the creation of new companies, whether open innovation processes facilitate access to funding sources by entrepreneurs or the analysis of business models based on open innovation for the creation of new companies.
\end{abstract}

Keywords: open innovation; entrepreneurship; bibliometrics; co-word analysis

\section{Introduction}

Open innovation (OI) is an emerging area that has followed several different strands due to the multidimensional nature of the concept of openness (Spender et al. 2017). It has been researched from different perspectives and levels of analysis but such research predominantly addresses the firm as the unit of analysis (Bogers et al. 2017). At the organizational level of analysis, OI is associated with entrepreneurial opportunities, processes, and outcomes. OI holds important implications for entrepreneurial activities in both new ventures and corporate ventures. And, OI approaches enable and create entrepreneurial opportunities for diverse types of organizations and in diverse types of contexts (Bogers et al. 2017).

Despite the interest for studying the relationship between entrepreneurship and OI, we found few studies that analyze both OI and entrepreneurship. For example, Spender et al. (2017) study the start-ups and OI but do not consider others types of entrepreneurship. The main aim of this paper is to understand the relationship between entrepreneurship and OI using bibliometric techniques. Therefore, two research questions have been defined: What are the main topics studied in the literature that combines both lines of research? What does the OI paradigm contribute to research on entrepreneurship?

We apply one bibliometric technique, the co-word analysis method, following Cobo et al. (2011), in a longitudinal framework to identify different themes treated by OI and entrepreneurship across the 
studied period. Bibliometric analyses enable us to perceive how a specific field of research has evolved over time. Similarly, they enable the synthesis and analysis of high volumes of scientific publications through the identification of the authors and main topics (Martens et al. 2016). This has allowed us to make an aggrupation proposal of the main terms obtained in the co-word analysis. The analysis results show a grouping around three clusters.

After accomplishing this objective, we will be better able to (a) facilitate a more realistic view of both fields, (b) enable us to describe the temporal evolution of publication activity and identify the most representative journals, authors, universities, and countries, (c) synthesize and organize existing knowledge through the identification of research clusters, and (d) identify potential areas for future research.

\section{Theoretical Background}

OI has become one of the most studied topics in innovation management literature. OI has been a topic of increasing interest in practice and academia (Bogers et al. 2017). From the practical perspective, a small group of innovation practitioners (Gassmann et al. 2010) developed the OI phenomenon. From a theoretical perspective, Chesbrough (2003a, 2003b) defined the OI concept and initiated a debate. In the following years, theory and practice evolved significantly (Bogers et al. 2017).

The basic premise of OI is an opening up of the innovation process. One of the most often used definitions of OI is "the use of purposive inflows and outflows of knowledge to accelerate internal innovation, and to expand the markets for external use of innovation, respectively" (Chesbrough 2006). Later, Chesbrough and Bogers (2014) define it as "a distributed innovation process based on purposively managed knowledge flows across organizational boundaries, in which OI is essentially a concept that resides at the level of the organization" (Bogers et al. 2017).

The OI paradigm emphasizes the importance of a wide range of external actors and sources for achieving and sustaining innovation (West and Bogers 2014). Rather than relying on internal R\&D, organizations are increasingly engaging in OI applied in others areas (Bogers et al. 2017) and the locus is changing from closed innovation to open innovation (Frishammar et al. 2018). This means that they have exchanged the do-it-yourself option in the innovation process for a rich dialogue of different partners working together (Montoro-Sánchez and Mora-Valentín 2012; Greco et al. 2016).

Therefore, previous studies, such as Gassmann et al. (2010), state the importance of developing OI theory more fully. Huizingh et al. (2011) affirm that there is a need for and benefit to expanding this field with new perspectives. Bogers et al. (2017) analyze the main perspectives and themes emerging in research on OI. They summarize the levels of analysis for OI: intra-organizational, organizational, extra-organizational, inter-organizational, industry, regional innovation systems and society. The relationship between OI and entrepreneurship is included at the organizational level of analysis and OI can help to identify opportunities for entrepreneurs, for different types of organizations and contexts. Bogers et al. (2017) state that "research would involve theories and constructs drawn from both fields (OI and entrepreneurship) and contribute to a deeper understanding of how varied OI approaches lead to varied types of entrepreneurial opportunities, processes and outcomes."

Bibliometric techniques allow a joint analysis of OI and entrepreneurship topics. There are several studies about OI using bibliometric analysis. Kovacs et al. (2015) conducted a literature review on OI using two bibliometric techniques: bibliographic coupling and co-citation analysis. Randhawa et al. (2016) offers a bibliometric review that combines the co-citation and text mining techniques to examine 321 articles on OI. Similarly, other studies conduct bibliometric analysis to investigate the development of the OI literature (Hossain and Anees-ur-Rehman 2016; Hossain et al. 2016). Seguí-Mas et al. (2016) present a bibliometric analysis of OI and absorptive capacity, while Medeiros et al. (2016) present a systematic review of the literature on OI in the food industry through a bibliometric analysis. De Paulo and Porto (2017) analyze OI in the solar energy sector using bibliometric techniques and social network analysis. De Paulo et al. (2017) provide a bibliometric analysis of OI in developed and emerging countries. 
We found several studies that analyze entrepreneurship using bibliometric analysis. A study by Schildt Henri A. (2004) uses bibliometric techniques to determine trends in entrepreneurship research. Cabeza-Ramírez et al. (2017) perform a systematic review of the literature using bibliometric techniques on the state of scientific production in the field of entrepreneurship. Shim et al. (2017) use co-word analysis to design agent-based models (ABMs) in entrepreneurship research. Volery and Mazzarol (2015) studied the evolution of the small business management and entrepreneurship fields through a bibliometric examination of all 660 articles published in the International Small Business Journal from 1982-2012. López-Fernández et al. (2016) perform a systematic review centered on the terms "entrepreneurship" and "family business" using a bibliometric analysis that combines co-citation and co-word analysis. Servantie et al. (2016) offer a bibliometric analysis of 567 articles on international entrepreneurship from 1989-2015. Albort-Morant and Ribeiro-Soriano (2016) conducted a bibliometric analysis of 445 articles to examine the international impact of business incubators. Rey-Martí et al. (2016) analyzed the phenomenon of social entrepreneurship using bibliometric techniques.

However, we found few studies that analyze OI and entrepreneurship using bibliometric analysis. For example, Spender et al. (2017) conducted a systematic literature review and constructed a state-of-the-art map of the start-ups in an OI context. Thus, our study conduct a widely analysis of entrepreneurship in an OI context though the co-word analysis.

\section{Research Protocol and Descriptive Analysis}

The objective of our search was to identify articles that contain an analysis of both topics: OI and entrepreneurship. The Web of Science (WoS) database was used for this task. Specifically, a search was executed for all documents published up to December 2017 that contained at least two of the keywords related to OI and entrepreneurship. The keyword identification was performed based on an initial literature review and through a brainstorming activity. Table 1 presents our search protocol.

Table 1. Search protocol.

\begin{tabular}{|c|c|c|c|c|}
\hline WoS Database & Time Period & Document Type & Search Criteria & Keywords \\
\hline $\begin{array}{l}\text { Social Science Citation Index (SSCI) } \\
\text { Science Citation Index (SCI) } \\
\text { Emerging Sources Citation Index (ESCI) }\end{array}$ & $\begin{array}{c}\text { Up to } \\
\text { December } 2017\end{array}$ & Article or Review & $\begin{array}{c}\text { Title, Keywords } \\
\text { and Abstract }\end{array}$ & $\begin{array}{l}\text { "open innovat" and } \\
\text { ("entrepreneur*" or } \\
\text { "incubat*" or "new firm*" } \\
\text { or "new venture*" or } \\
\text { "start-up*") }\end{array}$ \\
\hline
\end{tabular}

A total of 190 publications met these criteria. When each topic was queried individually (using the search protocol in Table 1), publications on OI numbered 1557, while publications on entrepreneurship numbered 291,403. Studies that combined both topics were significantly fewer. Next, we provide comments on the principal results of the descriptive analysis.

\subsection{Evolution over Time}

Figure 1 shows that most of the documents were published in recent years. Before 2010, articles on these topics appeared sporadically. In 2005, only three articles were published, two of which appeared in Research Policy and provided an industry perspective. In 2006, again, only three articles were published, two of which appeared in the International Journal of Technology Management and were exploratory in nature. In 2007, no publications met the search criteria. In 2008 and 2009, articles were more scattered and appeared in various non-specialized publications. In 2010 and 2011, the number of published studies exceeded 10, decreasing to 6 publications in 2012 and then returning to the prior level in 2013. In 2013, two special issues on entrepreneurship were published in the Service Industries Journal and the International Entrepreneurship and Management Journal. The number of published articles continued to increase in 2014 and 2015 (considering there were no special issues these years). However, in 2016 and 2017, the number of publications increased to 35 and 61 articles, respectively. 


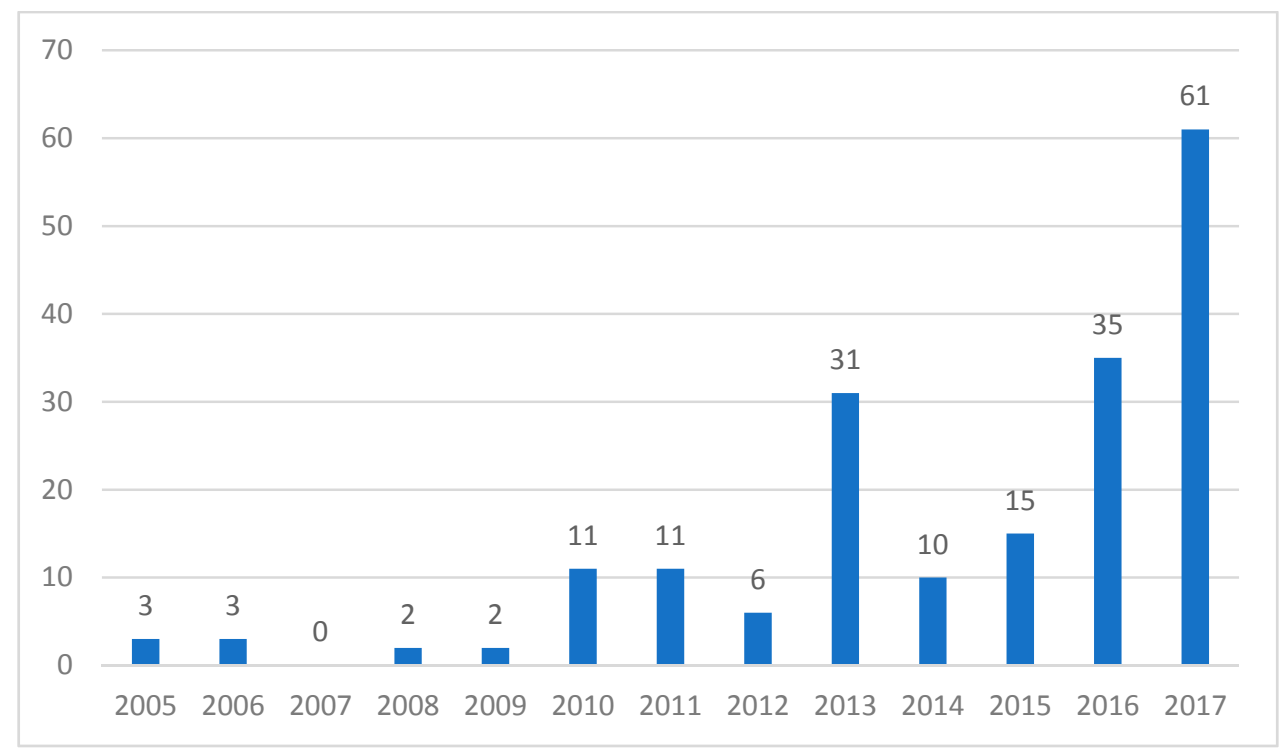

Figure 1. Evolution over time.

\subsection{Journals}

When analyzing the primary journals that published articles on the topics (Table 2), International Entrepreneurship and Management Journal stands out with 11 articles, followed by Service Industries Journal with 8. Both journals published special issues in 2013. The other journals exhibit a wider distribution of articles published over time except for the European Journal of Innovation Management, which published all of its relevant articles in 2017, and Technological Forecasting and Social Change, which published three of six articles in 2017 (Figure 2). When analyzing how SSCI classifies these journals using the WoS Journal Citation Reports (JCR) categories, we find that three are in the first quartile and that two are in in the ECSI category and had not yet been placed in a quartile. Most are in the "Business" and "Management" categories.

Table 2. Top journals.

\begin{tabular}{|c|c|c|c|}
\hline Journals & SSCI-JCR Categories & JCR 2016 Quartile & \# Articles \\
\hline \multirow{2}{*}{$\begin{array}{l}\text { International Entrepreneurship and Management } \\
\text { Journal }\end{array}$} & Business & Q3 & \multirow{2}{*}{11} \\
\hline & Management & Q3 & \\
\hline Service Industries Journal & Management & Q3 & 8 \\
\hline European Journal of Innovation Management & ESCI & - & 7 \\
\hline \multirow{2}{*}{ Research Policy } & Management & Q1 & \multirow{2}{*}{6} \\
\hline & Planning \& Development & Q1 & \\
\hline \multirow{2}{*}{ Technological Forecasting and Social Change } & Business & Q2 & \multirow{2}{*}{6} \\
\hline & Planning \& Development & Q1 & \\
\hline International Journal of Technology Management & Management & Q4 & 6 \\
\hline Technovation & Management & Q1 & 5 \\
\hline International Journal of Innovation Management & ESCI & - & 5 \\
\hline
\end{tabular}




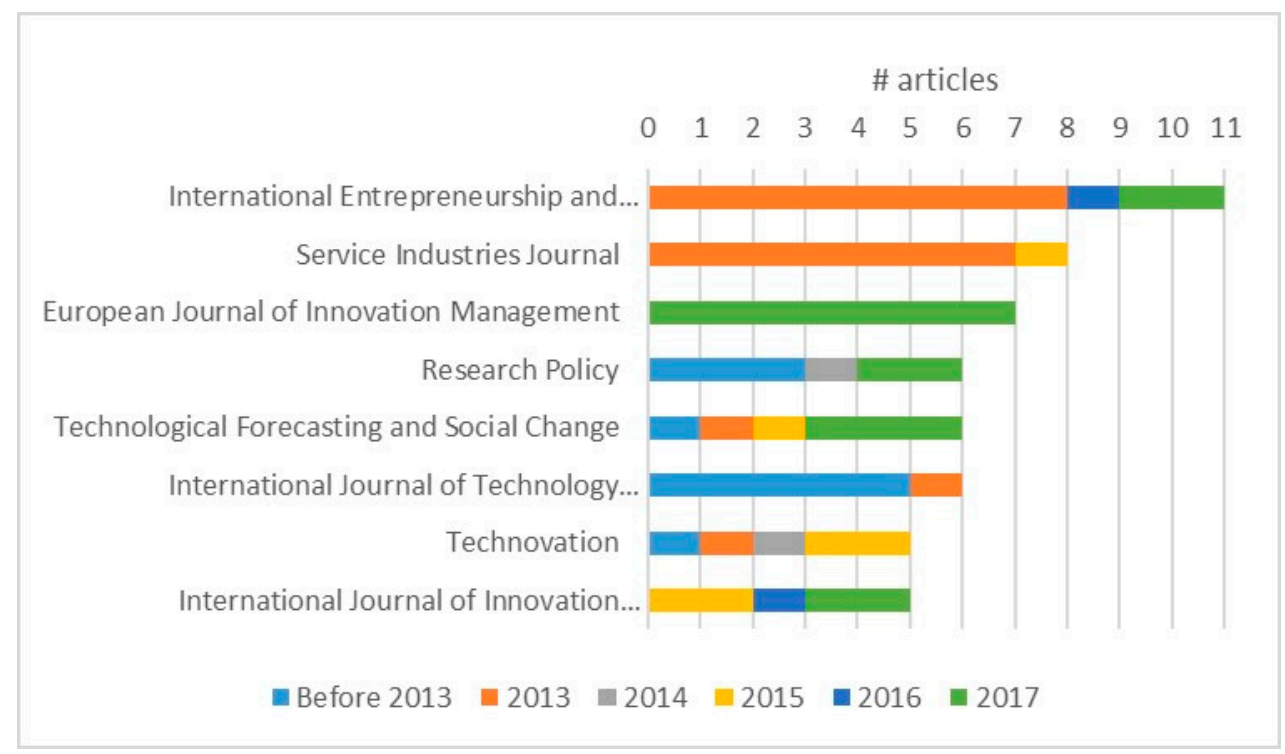

Figure 2. Evolution over time of articles by journal.

\subsection{Authors}

The author with the most publications is Chaston ${ }^{1}$, with 2.5 articles. His research analyses the relationship of OI with knowledge management and company performance. Cooke has published two papers, while Urbano, Yun, and Vanhaverbeke have an average equal to or greater than 1.4 because they have collaborated with other authors on several studies in this subject area (Table 3).

Table 3. Top authors.

\begin{tabular}{cc}
\hline Author & \# Articles \\
\hline Chaston, I. & 2.5 \\
Cooke, P. & 2.0 \\
Urbano, D. & 1.7 \\
Yun, J.J. & 1.5 \\
Vanhaverbeke, W. & 1.4 \\
Saguy, I.S. & 1.3 \\
Brown, T.E. & 1.3 \\
Park, K. & 1.3 \\
Shin, C. & 1.2 \\
Mortara, L. & 1.2 \\
Chesbrough, H.W. & 1.2 \\
Minshall, T. & 1.1 \\
\hline
\end{tabular}

Table 4 presents the authors with the greatest number of co-authors for their articles. Yun, Park, Mortara, Vanhaverbeke, and Urbano have collaborated the most (between four and five articles). Figure 3 shows the number of authors per publication for each year. Before 2013, most publications only had one or two authors. From 2013 to 2016, most articles had three authors. In 2017, the articles typically had two authors.

1 The statistics account for fractions of articles. That is, when a document has more than one author, each article is attributed proportionally to the number of co-authors. This criterion was also applied to the filiation analysis, considering both institutions and countries of origin. 
Table 4. Authors with the most co-authors.

\begin{tabular}{cc}
\hline Author & \# Articles \\
\hline Yun, J.J. & 5 \\
Park, K. & 4 \\
Mortara, L. & 4 \\
Vanhaverbeke, W. & 4 \\
Urbano, D. & 4 \\
Saguy, I.S. & 3 \\
Chesbrough, H.W. & 3 \\
Chaston, I. & 3 \\
Minshall, T. & 3 \\
\hline
\end{tabular}

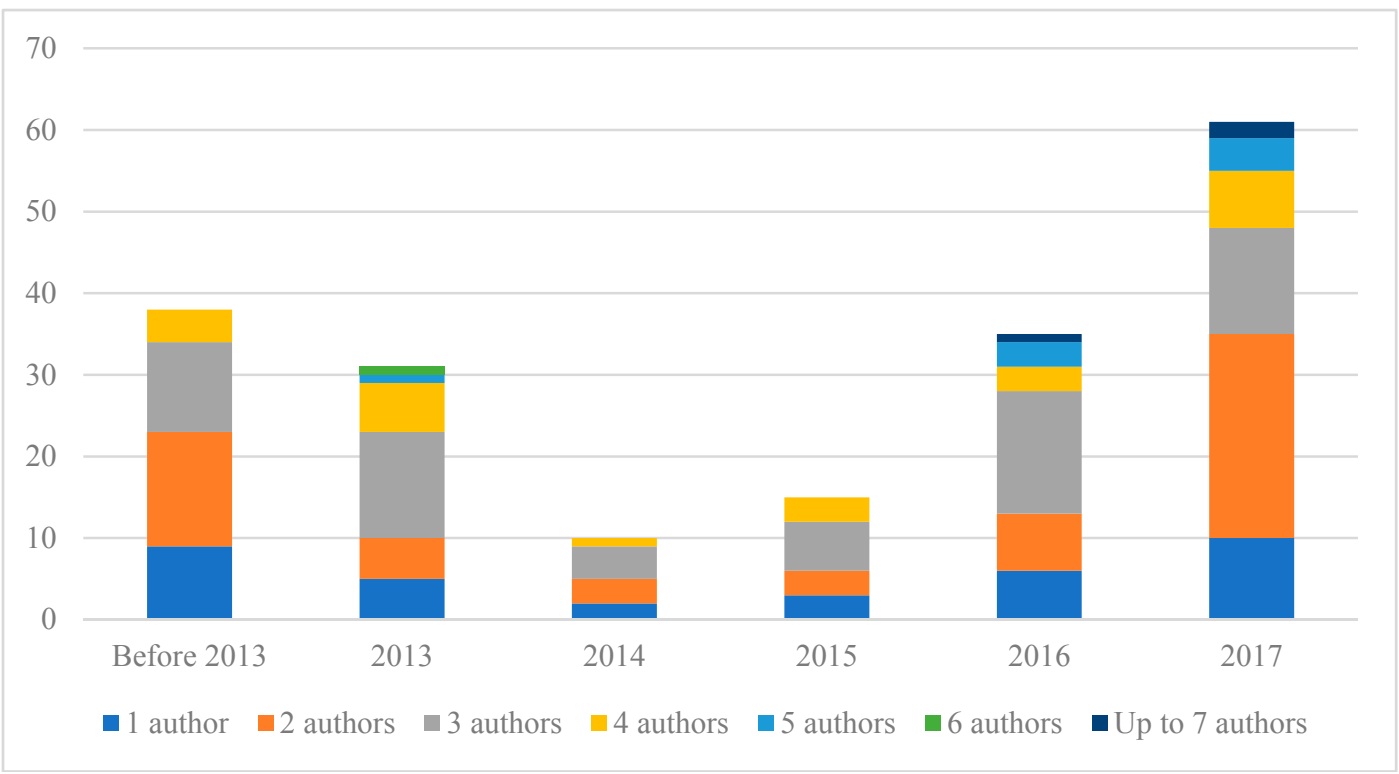

Figure 3. Number of authors per publication.

Regarding the authors' countries of origin (i.e., filiation, Table 5), Spain stands out with its significant scientific contribution (23 articles), ahead of research powers such as England (19 articles) and the United States (19 articles). It also highlights the scientific contributions of Italy and South Korea (over 11 articles).

Table 5. Top countries (author filiation).

\begin{tabular}{cc}
\hline Countries & \# Articles \\
\hline Spain & 23.17 \\
England & 18.94 \\
USA & 18.61 \\
Italy & 11.70 \\
South Korea & 11.33 \\
\hline
\end{tabular}

In addition to the analysis of the authors' origins, it is interesting to study the collaboration between countries (Figure 4). In this network that includes only those countries whose authors have published at least five papers, three clearly distinct groups emerge. On one hand is the red group, in which the United States and Canada stand out, along with a group of European countries. On the other hand, is the much less centralized blue group of four European countries plus Taiwan. In the green group, Spain and England join China and South Korea, two of the largest contributors. This group is much more centralized, at least regarding the first two countries. 


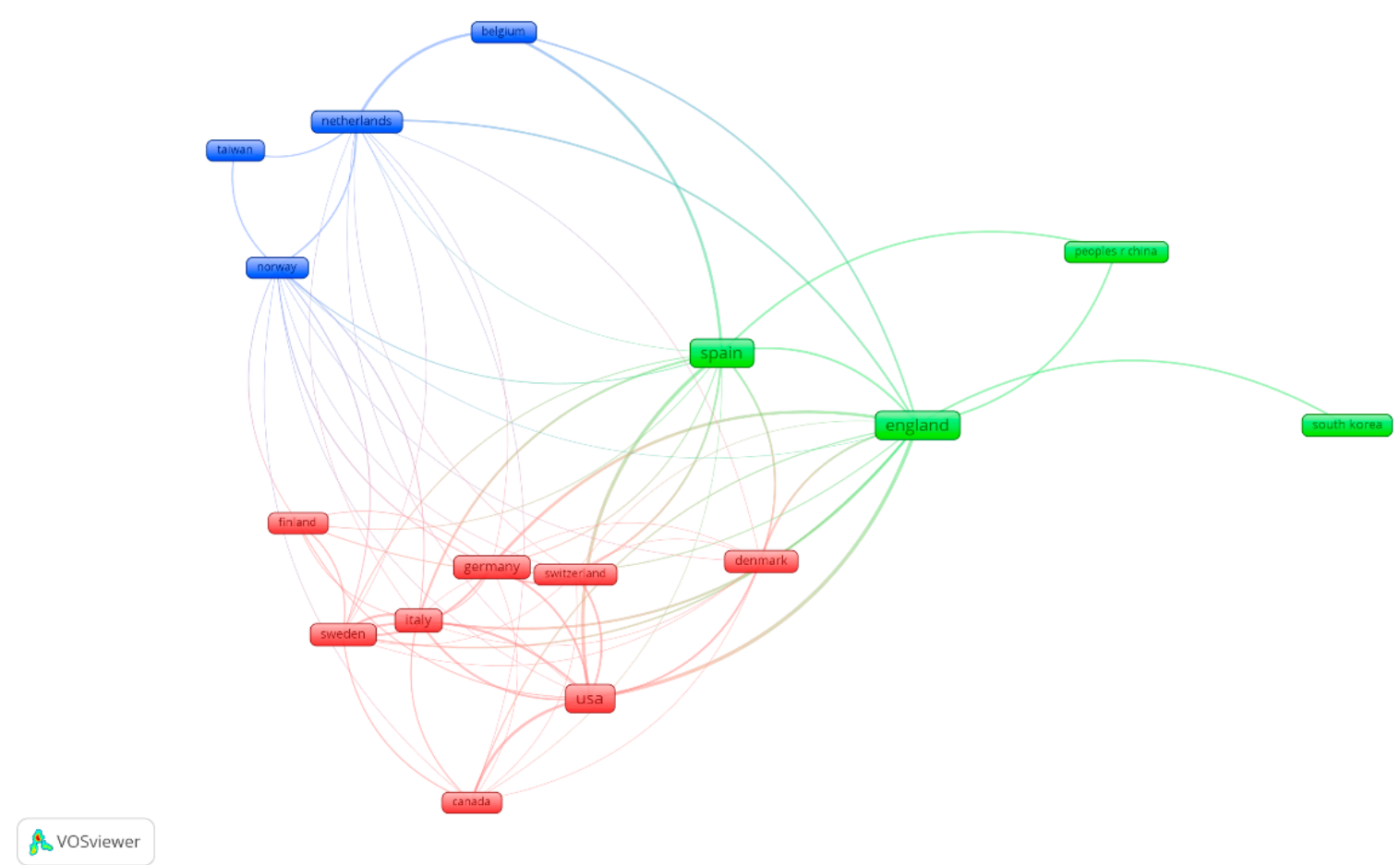

Figure 4. Collaboration between countries.

Considering the institutions to which the authors belong, the universities with the most published articles are the University of Cambridge, Lund University, and the Autonomous University of Barcelona (Table 6).

Table 6. Top universities.

\begin{tabular}{cc}
\hline University & \# Articles \\
\hline University of Cambridge & 3.9 \\
Lund University & 3 \\
Autonomous University of Barcelona & 2.8 \\
Daegu Gyeongbuk Institute of Science and Technology & 2.5 \\
Aarhus University & 2.2 \\
Valencia Polytechnic University & 2 \\
University of New Mexico & 2 \\
University of Seville & 2 \\
Complutense University of Madrid & 2 \\
Pontifical Catholic University of Peru & 2 \\
University of California - Berkeley & 2 \\
Valencia University & 2 \\
\hline
\end{tabular}

\subsection{Keywords}

In the analyzed articles, a total of 631 keywords suggested by the authors and 538 suggested by WoS were identified. In general, both keyword types provide information on the subject matter of the articles. Thus, it was determined to include both types in the analysis. Choi et al. (2011) suggest a normalization process with various elements, such as the merging of singular and plural forms, the normalization of abbreviations, the correction of alternative spellings (for example, derived from the use of scripts or uncorrected transcriptions), the merging of synonymous terms and the exclusion of terms with no specific meaning and that do not clearly indicate a topic. As a result of this normalization process, 330 keywords were excluded, leaving 507 keywords to be analyzed. Table 7 summarizes the statistics regarding the most repeated keywords. 
Table 7. Most frequent keywords.

\begin{tabular}{cc}
\hline Keyword & Frequency \\
\hline Open innovation & 145 \\
Entrepreneurship & 87 \\
Performance & 64 \\
Cooperation & 48 \\
Knowledge & 47 \\
Research and development (R\&D) & 47 \\
Innovation & 46 \\
Firm & 41 \\
Industry & 34 \\
Small and medium-sized enterprise (SME) & 28 \\
Network & 28 \\
Strategy & 27 \\
Absorptive capacity & 24 \\
Start-up & 23 \\
Technology & 20 \\
\hline
\end{tabular}

To clarify the identification of the knowledge structure of this research field, the following pages present the results of our co-word analysis. Zupic and Čater (2015) note that co-word analysis is the only bibliometric technique that deals directly with concepts extracted from documents and therefore focuses its attention on the knowledge structure of the area studied rather than its intellectual base, thus enabling the identification of the main topics of a research field and their relationships (Cobo et al. 2011).

\section{Co-Word Analysis}

Callon et al. (1983) indicate that the co-word analysis enables the representation of the intensity of associations between information items in textual data. He (1999) states that this method is used to study the co-occurrence of item pairs (for example, keywords) that are representative of a document (e.g., a research paper, patent or any other type of written document) to identify relationships between the ideas presented in those texts.

In terms of inputs and outputs, the co-word analysis is performed using a set of documents to which representative terms of the information they contain are associated. These terms are often referred to as keywords. When analyzing two terms in the same document, it is understood that there is a relationship between them, that is, that the subjects represented by those terms are linked. The more often that this coincidence is repeated, also termed co-occurrence, the greater the connection is. That is, the more documents there are that address both subjects simultaneously, the greater the intensity of the relationship.

The study of co-occurrences in a group of documents that represents a research field enables the identification of topic sets, that is, groups of terms that demonstrate a relationship between one another and with the rest of the terms that comprise the knowledge area. Thus, the result of a co-word analysis is a series of topic sets and their relationships that can be represented and analyzed with tools provided by social network theory.

Several approaches to conducting this analysis are described in the literature. The methodological proposal of Cobo et al. (2011) consists of four phases and uses the SCIMat tool. Van Eck and Waltman (2010) use the VOSViewer tool, which enables the use of VOS mapping and grouping algorithms (Van Eck and Waltman 2007, 2014; Van Eck et al. 2010; Waltman et al. 2010; Waltman and van Eck 2013) and has demonstrated performance that is superior to other techniques, such as multidimensional scaling (Van Eck et al. 2008). For this study, we have chosen to employ both techniques because they provide excellent alternatives for representing a knowledge structure by analyzing co-occurrences of keywords in a research area.

To execute this analysis, it was necessary to select a data source and then calculate the occurrences and co-occurrences of the keywords considered representative of each document. These data must be 
submitted to a normalization process, in which one typically must choose between different alternatives to construct the so-called similarity indexes. In our study, we chose the "Association Strength" index, which has advantages over other direct measures of similarity (such as those that adopt the number of co-occurrences between objects and adjust that number according to the number of occurrences and co-occurrences of each of the objects being measured), as demonstrated by Van Eck and Waltman (2009).

For our study, the analysis was performed by first configuring the co-word analysis as recommended by the VOSViewer software developers and then setting the minimum number of keyword occurrences to 10 to limit the analysis to those terms that are truly relevant in the literature analyzed.

\section{Results}

The constraint that at least 10 keyword occurrences must exist before the term can enter the network reduced the number of analyzed topics to 37 . The analysis results show a grouping around three clusters (Figure 5). The terms included in each cluster are presented in Tables 6-8. Based on these results, another grouping of terms within each cluster was performed. These blocks of terms within the clusters facilitated the interpretation and discussion of the results.

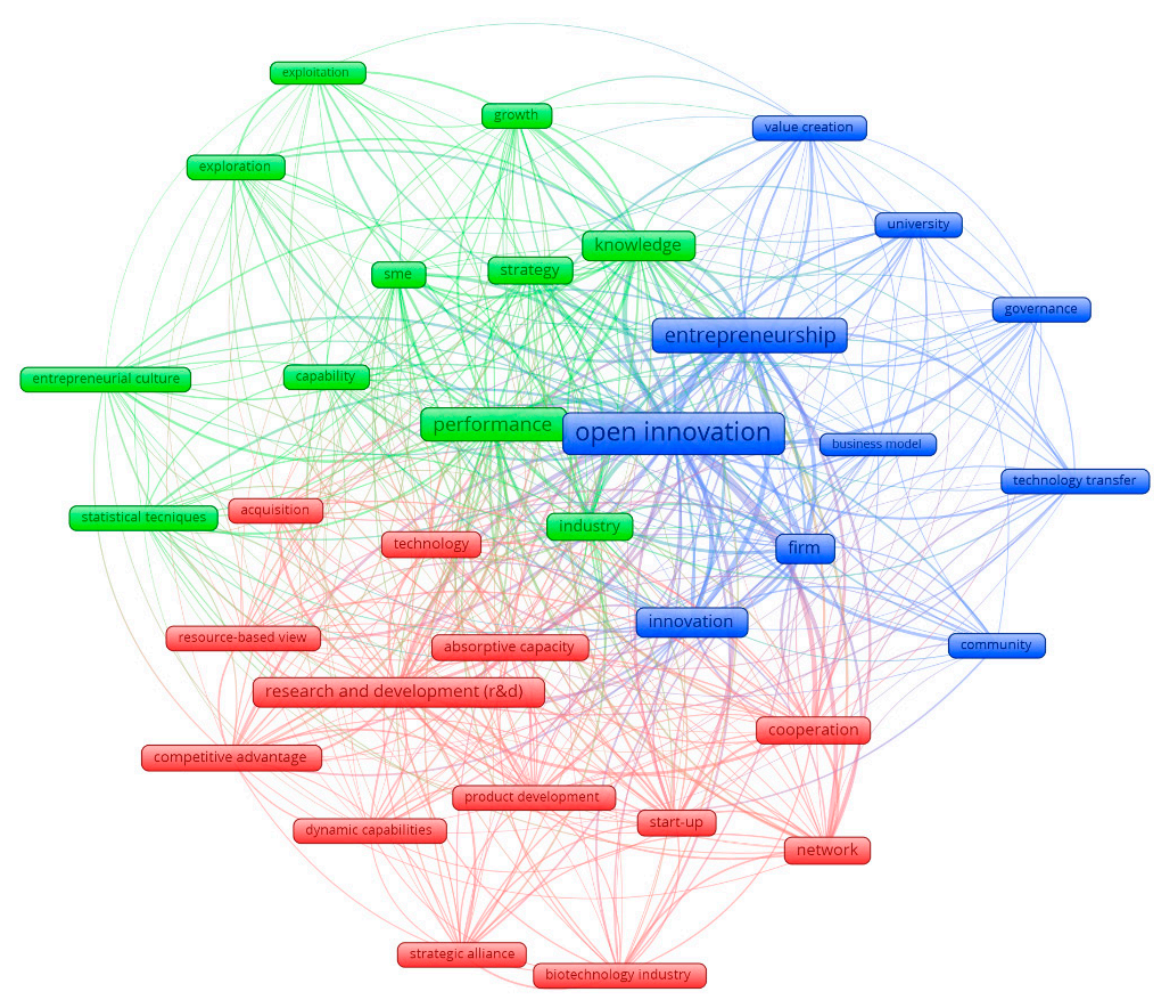

Figure 5. Clusters. 
Table 8. Red cluster.

\begin{tabular}{cc}
\hline Terms & Blocks \\
\hline $\begin{array}{c}\text { Product development } \\
\text { Research and development (R\&D) } \\
\text { Technology }\end{array}$ & Innovation management \\
\hline Start-up & Entrepreneurship \\
\hline $\begin{array}{c}\text { Cooperation } \\
\text { Network } \\
\text { Strategic alliance }\end{array}$ & Business cooperation \\
\hline Absorptive capacity & \\
Dynamic capabilities & \\
Resource-based view & Resources and capabilities \\
\hline Acquisition & \\
Biotechnology industry & General \\
Competitive advantage & \\
\hline
\end{tabular}

The first cluster (red) is the most numerous, with 13 terms that have been grouped into five blocks (Table 8). The first block is linked to innovation management: PRODUCT DEVELOPMENT, RESEARCH AND DEVELOPMENT (R\&D), and TECHNOLOGY (e.g., Du et al. 2014; Sakhdari 2016). The second block is related to entrepreneurship and includes the term START-UP (e.g., Homfeldt et al. 2017; Spender et al. 2017). The third block incorporates aspects related to business cooperation: COOPERATION, NETWORK and STRATEGIC ALLIANCE (e.g., Alberti and Pizzurno 2017; Huggins and Thompson 2017). The fourth block contains several terms related to resources and capabilities: ABSORPTIVE CAPACITY, DYNAMIC CAPABILITIES, and RESOURCE-BASED VIEW (e.g., Patton 2014; Venturini and Verbano 2017). Last, the fifth block includes other general terms, such as ACQUISITION, BIOTECHNOLOGY INDUSTRY, and COMPETITIVE ADVANTAGE (e.g., Mawson and Brown 2016; Patterson and Ambrosini 2015).

In the second cluster (green), 11 terms have been grouped into four blocks (Table 9). Noticeable are terms related to knowledge management: CAPABILITY, EXPLORATION, EXPLOITATION and KNOWLEDGE (e.g., Clausen et al. 2013; Noguera et al. 2013) and entrepreneurship: ENTREPRENEURIAL CULTURE (e.g., Knošková 2015). In addition, other terms appear that are related to results: GROWTH and PERFORMANCE (e.g., Lassala et al. 2013; Zhao et al. 2016). These terms demonstrate the need to use statistical techniques to understand the impact of OI and entrepreneurship on business results. In addition, more general terms appear here, such as INDUSTRY, SME, STATISTICAL TECNIQUES and STRATEGY (e.g., Chesbrough et al. 2014; Hossain and Kauranen 2016; Munir et al. 2016).

Table 9. Green cluster.

\begin{tabular}{cc}
\hline Terms & Blocks \\
\hline Capability & \\
Exploitation & \\
Exploration & Knowledge management \\
Knowledge & \\
\hline Entrepreneurial culture & Entrepreneurship \\
\hline Growth & Results \\
Performance & \\
\hline Industry & General \\
SME & \\
\hline Statistical techniques & \\
\hline
\end{tabular}


Last, in the third cluster (blue), 10 terms have been grouped into three blocks (Table 10). This cluster incorporates the two main topics of interest to our search: OPEN INNOVATION and ENTREPRENEURSHIP (e.g., Bengtsson 2017; Yun et al. 2016a). One can note terms related to OI, such as INNOVATION, with OI ecosystem agents, such as UNIVERSITY, FIRM, and COMMUNITY (e.g., Alexander et al. 2015; Miller et al. 2016) as well as the role of the state: GOVERNANCE (e.g., George et al. 2015). Regarding entrepreneurship, the term BUSINESS MODEL appears (e.g., Colombo et al. 2016; Yun et al. 2016b). Finally, a new term for measuring results emerges: VALUE CREATION (e.g., Herskovits et al. 2013).

Table 10. Blue cluster.

\begin{tabular}{cc}
\hline Terms & Blocks \\
\hline Open innovation & \\
Innovation & \\
University & \\
Firm & Open innovation \\
Community & \\
Governance & \\
Technology transfer & \\
\hline Entrepreneurship & Entrepreneurship \\
Business model & \\
\hline Value creation & Results \\
\hline
\end{tabular}

To complete this analysis, Figure 6 presents the evolution of the various topics over time. As explained by the legend, the different colors represent topics according to frequency of appearance, which facilitates perceiving the topics that stand out currently and those that have become neglected. This time-based analysis is limited due to the small number of years it covers.

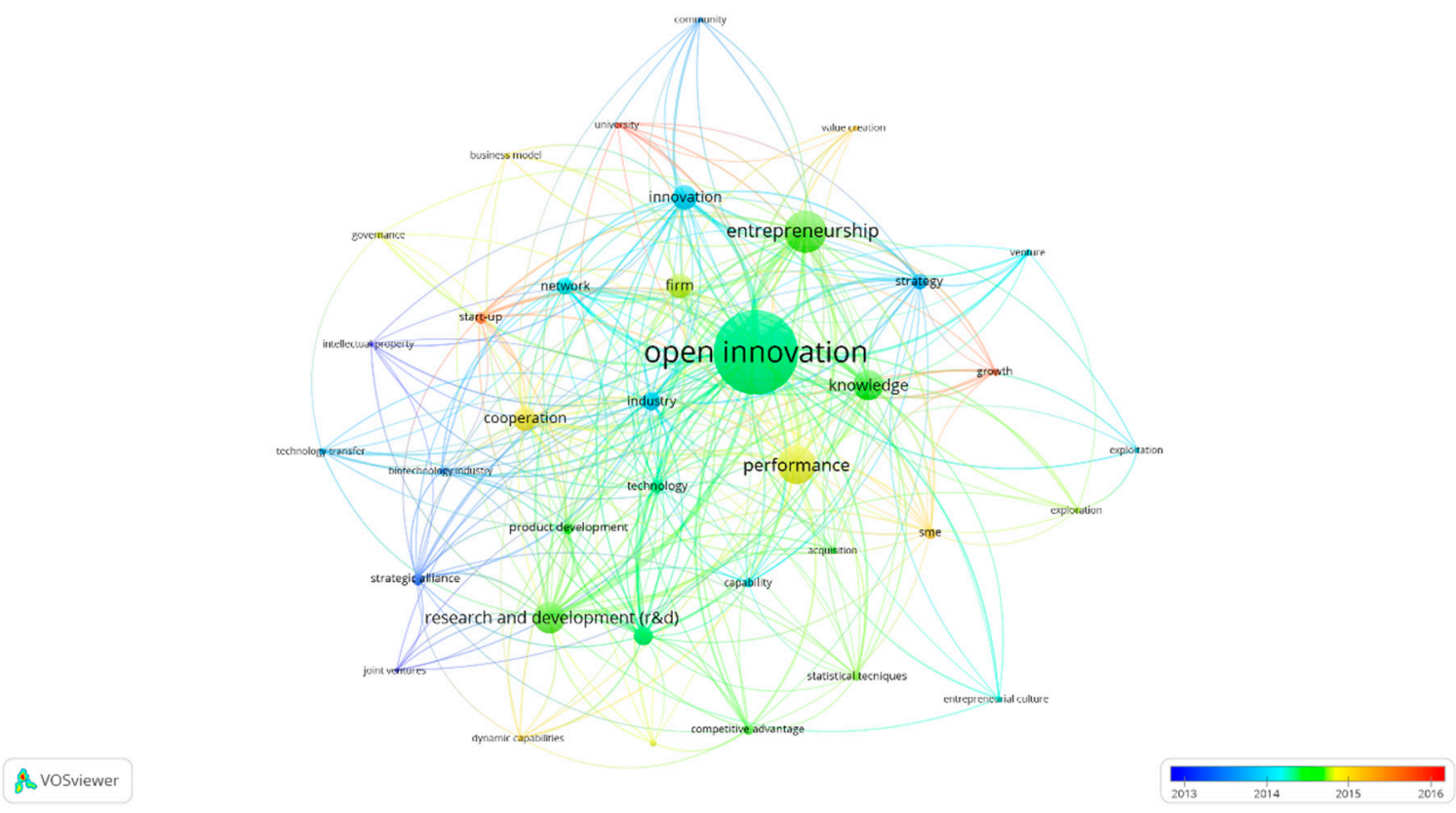

Figure 6. Evolution over time of topics.

In 2013, the most common terms are INTELLECTUAL PROPERTY, TECHNOLOGY TRANSFER, STRATEGIC ALLIANCES, and JOINT VENTURES. In 2014, the topics with the highest relative frequency are NETWORK, INNOVATION, INDUSTRY, and STRATEGY. Approaching 2015, OPEN 
INNOVATION, ENTREPREURSHIP, and KNOWLEDGE begin to stand out, while in 2015, the most common terms are PERFORMANCE and COOPERATION. Finally, the most frequent topics in 2016 and 2017 are START-UP, UNIVERSITY, and GROWTH.

\section{Discussion}

Based on the results, Table 11 presents our aggrupation of main topics by area in three clusters. In that sense, Frishammar et al. (2018) present the key dimensions of prior innovation audit frameworks (culture, resources \& capabilities, innovation process, business model) and their effect on innovation performance and competitive advantage. Our results show that the literature that focuses their attention in studying entrepreneurship in an OI context is considering those dimensions.

Table 11. Clusters and topic.

\begin{tabular}{ccc}
\hline Cluster & Open Innovation & Entrepreneurship \\
\hline 1. Red & $\begin{array}{c}\text { Innovation management } \\
\text { Cooperation } \\
\text { Resources theory }\end{array}$ & Start-up \\
\hline 2. Green & Knowledge management & Results \\
3. Blue & Open innovation & $\begin{array}{c}\text { Entrepreneurship } \\
\text { Business models }\end{array}$ \\
\hline
\end{tabular}

The first cluster consists of a series of studies that constitute the theoretical bases for the studies that analyze both subjects of interest to this research. Specifically, the first cluster includes studies inspired by the resources theory and based on the innovation management literature. In that sense, West and Bogers (2014) found that one gap in the OI literature "is a tendency in OI to use 'innovation' in a way inconsistent with earlier definitions in innovation management." In addition, the study of cooperation acquires special relevance. In that sense, collaboration has increasingly interest in OI literature. West and Bogers (2014) present a four-phase model to classify the previous research on how firms leverage external sources of innovation (outbound OI): (1) obtaining, (2) integrating, (3) commercializing external innovations, and (4) interaction between the firm and its collaborators. The last phase the interaction phase considers concepts such as co-creation, network collaboration and community innovation. Greco et al. (2016) explain that OI can follow one or more strategies: inbound OI (internal use of external knowledge); outbound OI (external use of internal knowledge); and coupled OI (active collaboration with partners to innovate). Furthermore, the term "start-up" implies a link between OI and entrepreneurship. In that case, Spender et al. (2017) present a state-of-the-art of the start-ups in an OI context.

The second cluster consists of studies that apply a knowledge management perspective and reveal the application of knowledge flows (exploitation and exploration) that relate to OI types (inbound, outbound and coupled). Some authors have analyzed the effect of knowledge exploitation to learn in using external sources of innovation (Hughes and Wareham 2010). Enkel et al. (2009) develop the "coupled" practice concept as a way of interaction between firms and innovative actors outside the firm including the flows of knowledge between them. There is greater interest in measuring the results of OI through statistical techniques. This cluster represents a consolidation of the literature on the culture of entrepreneurship.

In the third cluster, the term "open innovation" appears independently, and an interest in studying value creation is observed, as is the participation of agents such as universities, government, industry, and companies. The concept of entrepreneurship also emerges autonomously, and there is special interest in analyzing business models. West and Bogers (2014) find that a gap in prior research on OI is "a tendency to ignore the importance of business models," but Chesbrough (2003a) states that "OI 
combines internal and external ideas into architectures and systems whose requirements are defined by a business model" and one of the key goals of a business model is value creation.

These results complement and expand those found by Spender et al. (2017), who conducted a review of the literature on OI and start-ups. These authors analyzed 41 studies published before 2015 and organized the topics found in the OI and start-up literature into seven groups: (1) the role of start-up networks, (2) the actors who interact with start-ups in OI processes, (3) start-up ecosystems and their impact on OI processes, (4) the entrepreneurial dimension in the OI processes of start-ups, (5) the role of funding and funding institutions, (6) start-up performance in an OI context, and (7) knowledge stocks and flows in start-up OI processes. This article complements and extends the results obtained by Spender et al. (2017) in several aspects:

- Our study was not limited to start-ups but included any form of entrepreneurship, for which other keywords were included (e.g.: "entrepreneur*"; "incubat"*; "new firm*"; and "new venture ${ }^{* \prime \prime) . ~}$

- A literature review was conducted using a bibliometric technique, which provides rigor to the review and enables the analysis of larger volumes of information. Specifically, 190 articles were considered compared to the 41 studied by Spender et al. (2017).

- The time horizon was extended so that all the studies published up to December 2017 were considered, whereas Spender et al. (2017) only included works published up to 2015.

- The grouping of topics (clusters) studied in the literature was achieved by applying co-words analysis, which yields more objective and rigorous results.

If we compare the results of Spender et al. (2017) with ours, the following similarities emerge. The first topic commented on by Spender et al. (2017), "the role of start-up networks," is included in Cluster 1. Topic (2) ("actors who interact with the OI processes of start-ups"), Topic (6) ("performance of start-ups in an OI context"), and Topic (7) ("knowledge stocks and flows in the OI processes of start-ups") are among the Cluster 2 keywords. Last, Topic (3) ("start-up ecosystems and their impact on OI processes") and Topic (4) ("the entrepreneurial dimension in the OI processes of start-ups") are related to Cluster 3 . However, in this study, clusters of more complete subjects were found that advance the state of the art of this literature and suggest new areas of research.

\section{Conclusions}

In this paper, we have developed a previous literature review on OI and entrepreneurship. We attempt to answer two research questions. The first question was: What are the main topics studied in the literature that combine both research areas? The co-word analysis enabled us to identify the topics under study and group them into three clusters (Tables 8-10). This analysis was presented in the results section. The second research question was: What does the OI paradigm contribute to research on entrepreneurship? The discussion summarizes the answer to that question (Table 11).

This study has some contributions to the literature. It describes the temporal evolution of publication activity and the most representative journals, authors, universities, and countries. In addition, our results complement and expand those found by Spender et al. (2017) presenting state-of-the-art literature on entrepreneurship and OI through the identification of research clusters that allow us to propose some potential areas for future research.

This study also has implications for business practices. It helps entrepreneurs better understand OI and find examples of good practices for applying OI processes in their activities. In addition, this study sheds light on the effect of funding, on value creation, on cooperation, and on the advantages of networks for increasing the likelihood of success in entrepreneurial activity.

Finally, we suggest a direction for future research. Many newly created companies start small, which determines their first steps. In this regard, authors such as Bogers (2011) consider that OI practices can help start-ups "overcome both the liability of newness and the liability of smallness" (Spender et al. 2017). Future studies could more thoroughly analyze OI's advantages for small start-ups. 
Another issue relevant to entrepreneurship is funding. Spender et al. (2017) found funding to be one of the primary topics of studies on OI. However, this study did not find that funding is a focus in the literature on OI and entrepreneurship. Future research could consider an analysis of the main funding sources, its advantages and disadvantages as well as ways in which OI can facilitate access to funding sources for entrepreneurs.

Yet another aspect to pursue is the entrepreneurial dimension. Spender et al. (2017) define the entrepreneurial process in OI through activities such as "opportunity identification, resource mobilization, and the creation of an organization." They organized their results regarding the OI and start-up literature into three categories: "prior entrepreneurial experience," "entrepreneurial social capital" and "entrepreneurial policy." Future research could focus on defining the activities that comprise the entrepreneurial process in OI and on the analysis of the three categories proposed in this article through qualitative and quantitative studies.

Knowledge management is also addressed in previous studies. However, Spender et al. (2017) note an unresolved question: "How do start-ups manage knowledge flows among different partners?" The results of our research also indicate the significance of re-addressing this issue to analyze the management of knowledge flows in the ecosystem of entrepreneurial companies that follow OI processes.

Another relevant topic in the literature is the study of business results. Spender et al. (2017) highlighted the interest of several authors in analyzing the performance of start-ups in an OI context by identifying studies that analyzed innovation performance and organization performance. Our results add another: value creation. Future research could focus on conducting quantitative studies on the value creation generated by applying OI processes in entrepreneurial ventures.

Future research could also investigate the advantages of adopting an OI approach and the business models that can be developed. In this regard, several research questions could be addressed: How can one take advantage of OI when creating a new company? Which OI-based business models for creating new companies generate greater value? How to manage the complexity of business models based on new trends of innovation: openness, servitization, and digitalization? In that sense, Frishammar et al. (2018) present three major trends that are transformed the innovation landscape: (1) openness: from closed to more open models of innovation; (2) servitization: from providing physical products to industrial product-services; and (3) digitalization: from an analog to a highly digitalized world.

Author Contributions: Conceptualization, Marta Ortiz-de-Urbina-Criado and Eva-María Mora-Valentín; Data curation, Juan-José Nájera-Sánchez; Funding acquisition, Marta Ortiz-de-Urbina-Criado and Eva-María Mora-Valentín; Investigation, Marta Ortiz-de-Urbina-Criado, Juan-José Nájera-Sánchez and Eva-María Mora-Valentín; Methodology, Juan-José Nájera-Sánchez; Resources, Juan-José Nájera-Sánchez; Visualization, Marta Ortiz-de-Urbina-Criado, Juan-José Nájera-Sánchez and Eva-María Mora-Valentín; Writing - original draft, Marta Ortiz-de-Urbina-Criado and Eva-María Mora-Valentín.

Funding: This research was funded by Project ECO2015-67434-R of Spanish Ministry of Economy and Competitiveness (Spain).

Conflicts of Interest: The authors declare no conflict of interest.

\section{References}

Alberti, Fernando G., and Emanuele Pizzurno. 2017. Oops, I did it again! Knowledge leaks in open innovation networks with start-ups. European Journal of Innovation Management 20: 50-79. [CrossRef]

Albort-Morant, Gema, and Domingo Ribeiro-Soriano. 2016. A bibliometric analysis of international impact of business incubators. Journal of Business Research 69: 1775-79. [CrossRef]

Alexander, Allen T., Kristel Miller, and Sean Fielding. 2015. Open for business: Universities, entrepreneurial academics and open innovation. International Journal of Innovation Management 19: 1540013. [CrossRef]

Bengtsson, Lars. 2017. A comparison of university technology transfer offices' commercialization strategies in the Scandinavian countries. Science and Public Policy 44: 565-77. [CrossRef] 
Bogers, Marcel. 2011. The open innovation paradox: Knowledge sharing and protection in R\&D collaborations. European Journal of Innovation Management 14: 93-117. [CrossRef]

Bogers, Marcel, Ann-Kristin Zobel, Allan Afuah, Esteve Almirall, Sabine Brunswicker, Linus Dahlander, Lars Frederiksen, Annabelle Gawer, Marc Gruber, Stefan Haefliger, and et al. 2017. The open innovation research landscape: Established perspectives and emerging themes across different levels of analysis. Industry and Innovation 24: 8-40. [CrossRef]

Cabeza-Ramírez, Luis Javier Cabeza, Sandra María Sánchez-Cañizares, and Fernando J. Fuentes-García. 2017. Entrepreneurship as a dynamic field of study: A bibliometric analysis of research output. Tourism E Management Studies 13: 59-71. [CrossRef]

Callon, Michel, Jean-Pierre Courtial, William A. Turner, and Serge Bauin. 1983. From translations to problematic networks: An introduction to co-word analysis. Social Science Information 22: 191-235. [CrossRef]

Chesbrough, Henry. 2003a. Open Innovation: The New Imperative for Creating and Profiting from Technology. Boston: Harvard Business School Press, ISBN 978-1422102831.

Chesbrough, Henry. 2003b. The era of open innovation. MIT Sloan Management Review 44: 35-41.

Chesbrough, Henry. 2006. Open Business Models: How to Thrive in the New Innovation Landscape. Boston: Business School Press, ISBN 978-1422104279.

Chesbrough, Henry, and Marcel Bogers. 2014. Explicating open innovation: Clarifying an emerging paradigm for understanding innovation. In New Frontiers in Open Innovation. Edited by Henry Chesbrough, Wim Vanhaverbeke and Joel West. Oxford: Oxford University Press, pp. 3-28. Available online: https: / / ssrn.com/abstract=2427233 (accessed on 7 May 2018).

Chesbrough, Henry, Sohyeong Kim, and Alice Agogino. 2014. Chez panisse: Building an open innovation ecosystem. California Management Review 56: 144-71. [CrossRef]

Choi, Jinho, Sangyoon Yi, and Kun C. Lee. 2011. Analysis of keyword networks in MIS research and implications for predicting knowledge evolution. Information \& Management 48: 371-81. [CrossRef]

Clausen, Tommy H., Tor Korneliussen, and Einar L. Madsen. 2013. Modes of innovation, resources and their influence on product innovation: Empirical evidence from R\&D active firms in Norway. Technovation 33: 225-33. [CrossRef]

Cobo, Manuel J., Antonio G. López-Herrera, Enrique Herrera-Viedma, and Francisco Herrera. 2011. An approach for detecting, quantifying, and visualizing the evolution of a research field: A practical application to the Fuzzy Sets Theory field. Journal of Informetrics 5: 146-66. [CrossRef]

Colombo, Massimo G., Douglas Cumming, Ali Mohammadi, Cristina Rossi-Lamastra, and Anu Wadhwa. 2016. Open business models and venture capital finance. Industrial and Corporate Change 25: 353-70. [CrossRef]

De Paulo, Alex F., and Geciane S. Porto. 2017. Solar energy technologies and open innovation: A study based on bibliometric and social network analysis. Energy Policy 108: 228-38. [CrossRef]

De Paulo, Alex F., Luísa C. Carvalho, Maria Teresa G. V. Costa, Jose Eduardo F. Lopes, and Simone V. R. Galina. 2017. Mapping open innovation: A Bibliometric review to compare developed and emerging countries. Global Business Review 18: 291-307. [CrossRef]

$\mathrm{Du}$, Jingshu, Bart Leten, and Wim Vanhaverbeke. 2014. Managing open innovation projects with science-based and market-based partners. Research Policy 43: 828-40. [CrossRef]

Enkel, Ellen, Oliver Gassmann, and Henry Chesbrough. 2009. Open R\&D and open innovation: Exploring the phenomenon. RED Management 39: 311-16. [CrossRef]

Frishammar, Johan, Anders Richtnér, Anna Brattström, Mats Magnusson, and Jennie Björk. 2018. Opportunities and challenges in the new innovation landscape: Implications for innovation auditing and innovation management. European Management Journal. [CrossRef]

Gassmann, Oliver, Ellen Enkel, and Henry Chesbrough. 2010. The future of open innovation. RED Management 40: 213-21. [CrossRef]

George, Gerard, Rekha Rao-Nicholson, Christopher Corbishley, and Rahul Bansal. 2015. Institutional entrepreneurship, governance, and poverty: Insights from emergency medical response services in India. Asia Pacific Journal of Management 32: 39-65. [CrossRef]

Greco, Marco, Michele Grimaldi, and Livio Cricelli. 2016. An analysis of the open innovation effect on firm performance. European Management Journal 34: 501-16. [CrossRef]

He, Qin. 1999. Knowledge discovery through co-word analysis. Library Trends 48: 133-59. 
Herskovits, Ruben, Mercedes Grijalbo, and Javier Tafur. 2013. Understanding the main drivers of value creation in an open innovation program. International Entrepreneurship and Management Journal 9: 631-40. [CrossRef]

Homfeldt, Felix, Alexandra Rese, Hanno Brenner, Daniel Baier, and Til F. Schaefer. 2017. Identification and generation of innovative ideas in the procurement of the automotive industry: The case of Audi AG. International Journal of Innovation Management 21: 1750053. [CrossRef]

Hossain, Mokter, and Muhammad Anees-ur-Rehman. 2016. Open innovation: An analysis of twelve years of research. Strategic Outsourcing 9: 22-37. [CrossRef]

Hossain, Mokter, and Ilkka Kauranen. 2016. Open innovation in SMEs: A systematic literature review. Journal of Strategy and Management 9: 58-73. [CrossRef]

Hossain, Mokter, Islam K. M. Zahidul, Mohammad Abu Sayeed, and Ilkka Kauranen. 2016. A comprehensive review of open innovation literature. Journal of Science and Technology Policy Management 7: 2-25. [CrossRef]

Huggins, Robert, and Piers Thompson. 2017. Entrepreneurial networks and open innovation: The role of strategic and embedded ties. Industry and Innovation 24: 403-35. [CrossRef]

Hughes, Benjamin, and Jonathan Wareham. 2010. Knowledge arbitrage in global pharma: A synthetic view of absorptive capacity and open innovation. RED Management 40: 324-43. [CrossRef]

Huizingh, Elko, Steffen Conn, and Marko Torkkeli. 2011. Editorial: ISPIM special issue on open innovation. Technovation 31: 1. [CrossRef]

Knošková, Lubica. 2015. Innovation processes and entrepreneurial culture for radical innovations. Amfiteatru Economic 17: 342-57.

Kovacs, Adrián, Bart Van Looy, and Bruno Cassiman. 2015. Exploring the scope of open innovation: A bibliometric review of a decade of research. Scientometrics 104: 951-83. [CrossRef]

Lassala, Carlos, Alexandre Momparler, and Pedro Carmona. 2013. Determinants of performance of independent financial advisors. International Entrepreneurship and Management Journal 9: 581-601. [CrossRef]

López-Fernández, María Concepción, Ana María Serrano-Bedia, and Marta Pérez-Pérez. 2016. Entrepreneurship and family firm research: A bibliometric analysis of an emerging field. Journal of Small Business Management 54: 622-39. [CrossRef]

Martens, Cristina D. P., Fabrício M. Lacerda, Ana C. Belfort, and Henrique M. Rodrigues de Freitas. 2016. Research on entrepreneurial orientation: Current status and future agenda. International Journal of Entrepreneurial Behavior \& Research 22: 556-83. [CrossRef]

Mawson, Suzanne, and Ross Brown. 2016. Entrepreneurial acquisitions, open innovation and UK high growth SMEs. Industry and Innovation 24: 382-402. [CrossRef]

Medeiros, Giovanna, Erlaine Binotto, Silvia Caleman, and Thiago Florindo. 2016. Open innovation in agrifood chain: A systematic review. Journal of Technology Management E Innovation 11: 108-16. [CrossRef]

Miller, Kristel, Rodney McAdam, Sandra Moffett, Allen Alexander, and Pushyarag Puthusserry. 2016. Knowledge transfer in university quadruple helix ecosystems: An absorptive capacity perspective. RED Management 46: 383-99. [CrossRef]

Montoro-Sánchez, Ángeles, and Eva-María Mora-Valentín. 2012. Editorial. Open innovation and transitions: Redefining the boundaries. International Journal of Transitions and Innovation Systems 2: 111-16. Available online: http:/ / www.inderscience.com/editorials/f681125712910431.pdf (accessed on 10 May 2018).

Munir, Hussan, Krzysztof Wnuk, and Per Runeson. 2016. Open innovation in software engineering: A systematic mapping study. Empirical Software Engineering 21: 684-723. [CrossRef]

Noguera, María, Claudia Álvarez, and David Urbano. 2013. Socio-cultural factors and female entrepreneurship. International Entrepreneurship and Management Journal 9: 183-97. [CrossRef]

Patterson, William, and Veronique Ambrosini. 2015. Configuring absorptive capacity as a key process for research intensive firms. Technovation 36: 77-89. [CrossRef]

Patton, Dean. 2014. Realising potential: The impact of business incubation on the absorptive capacity of new technology-based firms. International Small Business Journal 32: 897-917. [CrossRef]

Randhawa, Krithika, Ralf Wilden, and Jan Hohberger. 2016. A bibliometric review of open innovation: Setting a research agenda. Product Innovation Management 33: 750-72. [CrossRef]

Rey-Martí, Andrea, Domingo Ribeiro-Soriano, and Daniel Palacios-Marqués. 2016. A bibliometric analysis of social entrepreneurship. Journal of Business Research 69: 1651-55. [CrossRef]

Sakhdari, Kama. 2016. Absorptive capacity: Review and research agenda. Journal of Organisational Studies and Innovation 3: 34-50. 
Schildt Henri A., Antti Sillanpää. 2004. The Field of Entrepreneurship: A Bibliometric Assessment. Working Paper No 2004/1. Espoo: Helsinki University of Technology Institute of Strategy and International Business.

Seguí-Mas, Elies, Elisa Signes-Pérez, Faustino Sarrión-Viñes, and Joaquín Alegre-Vidal. 2016. Anàlisi bibliomètrica de la literatura internacional sobre innovació oberta i capacitat d'absorció. Intangible Capital 12: 51-72. [CrossRef]

Servantie, Vinciane, Matthieu Cabrol, Gilles Guieu, and Jean-Pierre Boissin. 2016. Is international entrepreneurship a field? A bibliometric analysis of the literature (1989-2015). Journal of International Entrepreneurship 14: 168-212. [CrossRef]

Shim, Jaehu, Martin Bliemel, and Myeonggil Choi. 2017. Modeling complex entrepreneurial processes: A bibliometric method for designing agent-based simulation models. International Journal of Entrepreneurial Behavior \& Research 23: 1052-70. [CrossRef]

Spender, John-Christopher, Vincenzo Corvello, Michele Grimaldi, and Pierluigi Rippa. 2017. Startups and open innovation: A review of the literature. European Journal of Innovation Management 20: 4-30. [CrossRef]

Van Eck, Nees Jan, and Ludo Waltman. 2007. Bibliometric mapping of the computational intelligence field. International Journal of Uncertainty, Fuzziness and Knowledge-Based Systems 15: 625-45. [CrossRef]

Van Eck, Nees Jan, and Ludo Waltman. 2009. How to normalize cooccurrence data? An analysis of some well-known similarity measures. Journal of the American Society for Information Science E Technology 60: 1635-51. [CrossRef]

Van Eck, Nees Jan, and Ludo Waltman. 2010. Software survey: VOSviewer, a computer program for bibliometric mapping. Scientometrics 84: 523-38. [CrossRef] [PubMed]

Van Eck, Nees Jan, and Ludo Waltman. 2014. Visualizing bibliometric networks. In Measuring Scholarly Impact: Methods and Practice. Edited by Ying Ding, Ronald Rousseau and Dietmar Wolfram. Cham: Springer International Publishing, pp. 285-320.

Van Eck, Nees-Jan, Ludo Waltman, Rommert Dekker, and Jan Van den Berg. 2008. An experimental comparison of bibliometric mapping techniques. Paper presented at 10th International Conference on Science and Technology Indicators, Vienna, Austria, September 18.

Van Eck, Nees Jan, Ludo Waltman, Rommert Dekker, and Jan van den Berg. 2010. A comparison of two techniques for bibliometric mapping: Multidimensional scaling and VOS. Journal of the American Society for Information Science and Technology 61: 2405-16. [CrossRef]

Venturini, Karen, and Chiara Verbano. 2017. Open innovation in the public sector: Resources and performance of research-based spin-offs. Business Process Management Journal 23: 1337-58. [CrossRef]

Volery, Thierry, and Tim Mazzarol. 2015. The evolution of the small business and entrepreneurship field: A bibliometric investigation of articles published in the International Small Business Journal. International Small Business Journal 33: 374-96. [CrossRef]

Waltman, Ludo, and Nees Jan van Eck. 2013. Source normalized indicators of citation impact: An overview of different approaches and an empirical comparison. Scientometrics 96: 699-716. [CrossRef]

Waltman, Ludo, Nees Jan van Eck, and Ed C. M. Noyons. 2010. A unified approach to mapping and clustering of bibliometric networks. Journal of Informetrics 4: 629-35. [CrossRef]

West, Joel, and Marcel Bogers. 2014. Leveraging external sources of innovation: A review of research on open innovation. Journal of Product Innovation Management 31: 814-31. [CrossRef]

Yun, Jinhyo J., Kyungbae Park, Janghyun Kim, and Jeongho Yang. 2016a. Open innovation effort, entrepreneurship orientation and their synergies onto innovation performance in SMEs of Korea. Science Technology and Society 21: 366-90. [CrossRef]

Yun, Jinhyo J., Jeongho Yang, and Kyungbae Park. 2016b. Open innovation to business model: New perspective to connect between technology and market. Science Technology and Society 21: 324-48. [CrossRef]

Zhao, Shukuan, Yu Sun, and Xiaobo Xu. 2016. Research on open innovation performance: A review. Information Technology and Management 17: 279-87. [CrossRef]

Zupic, Ivan, and Tomaž Čater. 2015. Bibliometrics methods in management and organizations. Organizational Research Methods 18: 429-72. [CrossRef]

(C) 2018 by the authors. Licensee MDPI, Basel, Switzerland. This article is an open access article distributed under the terms and conditions of the Creative Commons Attribution (CC BY) license (http:/ / creativecommons.org/licenses/by/4.0/). 